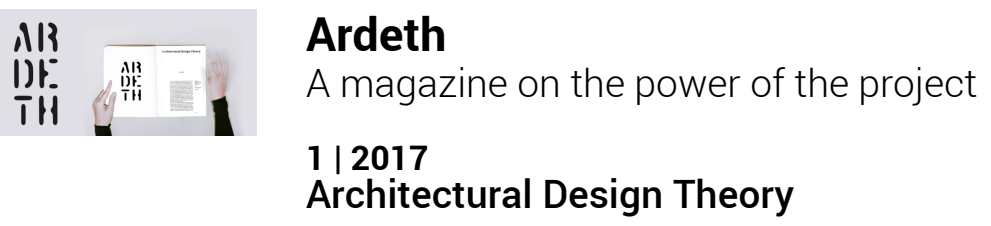

\title{
A Theory of "Design by Research"; Mapping Experimentation in Architecture and Architectural Design
}

Marc Schoonderbeek

\section{(2) OpenEdition \\ Journals}

Electronic version

URL: http://journals.openedition.org/ardeth/962

ISSN: 2617-934X

\section{Publisher}

Rosenberg \& Sellier

\section{Printed version}

Date of publication: 1 October 2017

Number of pages: 63-79

ISSN: 2532-6457

\section{Electronic reference}

Marc Schoonderbeek, " A Theory of "Design by Research"; Mapping Experimentation in Architecture and Architectural Design », Ardeth [Online], 1 | 2017, Online since 01 October 2017, connection on 13 November 2020. URL : http://journals.openedition.org/ardeth/962 


\section{A Theory of \\ "Design by Research"; \\ Mapping Experimentation in \\ Architecture and \\ Architectural Design}

Marc Schoonderbeek

Abstract

In an age of increased fragmentation, orientation and specialization, architectural research that aims at breaking new theoretical ground and introducing new techniques and methods of design makes sense only if it is able to formulate and make explicit an implied "discursive whole". The article argues that cartographic means enable architects to chart characteristics of space and explores the extent to which mapping in architectural design can potentially inform architectural construct. This form of activating spatial analysis is both projective and performative. By identifying three basic principles of activation, the article defines mapping as an instrumentalization, an operationalization or a conceptualization of the spatial map.
Affiliation

Border Conditions

\& Territories

Research Group

Department of Ar-

chitecture, Faculty

of Architecture

Delft University of

Technology.

M.G.H.Shoonder beek@tudelft.nl

DOI

10.17454/ARDETH01.05

ARDETH\#01 


\section{Nowadays it is clear that contemporary architectural research cannot be reduced to a singular trajectory of thought and analysis.}

\section{Introduction}

How can architecture, or architectural research, nowadays operate in a field that Manfredo Tafuri had, at one point, described as a "no man's land, the boundaries of which are forever shifting» (Tafuri, 1979:

157)? How can one possibly, in an age of increased fragmentary orientation and specialization, define an architectural research program of which the intent and ambition is to break new theoretical ground and to introduce new techniques and methods of design intrinsically connected to this theoretical framework. Where Tafuri still had considerable difficulty with the 'hotchpotch' of architectural production (Tafuri, 1979: 143) and the fragmentary state of the discipline in his era, any current attempt at an architectural discursive act(ion) has long accepted the un-orderly state of contemporary architectural design and research practices, even though attempts at an occasional "rappèl a l'ordre" resurface in international or local debates. Nowadays it is clear that contemporary architectural research cannot be reduced to a singular trajectory of thought and analysis, just as the practice of architectural design is not founded on a singular theoretical structure, nor that spatial analysis is confined to one disciplinary form or that the understanding of an architectural object would be limited to one all-encompassing idea. It would seem, in short, that within the general contemporary "hotchpotch" of approaches and positions it is apparent that any architectural research program nowadays only makes sense when one attempts, as any striving towards a research "program" would indicate, to structure an implied "discursive whole", based on the incorporation of the diversification of architectural knowledge, tools and methods.

\section{Architecture and the Problem of Discipline}

The specific task Tafuri had set himself was to properly organize and dissect architectural historical material for its own sake. This historical material, in total fact actually the larger discursive tradition of architecture, was not to be purposely investigated for contemporary architectural design practices themselves, in other words not to try to make historical material operational, but to be able to dissect any architectural statement towards an understanding of its cultural 
activities and towards a clarification of its embedded meaning(s). The "tendency" Tafuri (1976) had attempted to formulate was, naturally, not an isolated case, but formed one of the more ambitious endeavors at the time. Other attempts to make sense of the debris caused by the ongoing societal, scientific and economic developments and upheavals of the Sixties and Seventies, combined with an emerging historical awareness, gave rise to a great variety of architectural and urban theories that attempted to, still, provide for an all-encompassing theory of architecture. During this period, however, the problematic nature of such endeavors was clearly visible, if only in hindsight. Though not consciously acknowledged, the positions in this period are characterized by their great emphasis on the limitation of scope, the fragmentation of the experience of the city, certain relativisms towards issues of "truth", as well as an awareness of the claimed "bankruptcy of the meta-narrations" in historiography (Lyotard, 1984).

This period of intense reconsideration of the specific knowledge and tools of architecture was followed, during the Eighties, by the emergence of deconstruction or, more exponentially, the expanded discursive interest around the field of architecture ${ }^{1}$. The aftereffect of two decades of intense study of architecture's rich history, which established a clear core (and an assumed autonomy) of the architectural discipline, was the infection of the profession with other disciplines. Cross-, trans- and multi-disciplinary investigations allowed for an assessment of the outer edges of the architectural discipline, which not only clarified the position of the architectural discipline in the larger field of discursive practices, but also explored, and thus opened, the discourse to the shared territories of disciplinary action. Simultaneously, or perhaps even coming out of these explorations, is the emergence of "research" as a separate and distinctive field of operation within architecture (next to design, theory, history and criticism).

\section{Theory versus Research}

Starting with Vitruvius's ten books on architecture, the historical origin of "architectural theory" is located in the great tradition of architectural treatise writing. Through the written and drawn accounts of
1 - The clearest and extensive attempt at clarifying the origins of deconstruction in architecture being rooted in Derrida's philosophical œuvre has been made by Mark Wigley in his book The Architecture of Deconstruction; Derrida's Haunt, Cambridge (MA) London, The MIT

Press, 1993. See also Andreas Papadakis, Catherine Cooke and Andrew Benjamin (eds.), Deconstruction, Omnibus Volume, London, Academy Editions, 1989. 
During the

Enlightenment, architectural treatises generally gained more precision through the attempt to provide for the scientific basis of architecture based on principles of reason. a treatise, architectural and building practices are extended to include at least two distinctive activities, namely the prescriptive gathering and systemized ordering of knowledge; and the possibility of debate and discussion of the inherent logic and meaning of these practices. Architectural theory, at least until the $18^{\text {th }}$ century, maintained and cultivated this prescriptive character by insisting on its basic objective to provide for a systematic body of knowledge, combined with a set of instructions that "grounds" architectural production. During the Enlightenment, architectural treatises generally gained more precision through the attempt to provide for the scientific basis of architecture based on principles of reason (Durand, 2005). Still, in all these cases, theory was considered to be the proper means to develop a consistent way of thinking and working in architecture. In the course of more recent times, however, theory started to increasingly emphasize its reflective role, i.e. the second category of tracing out the inherent logic and meaning of architecture mentioned above, and transformed into architectural criticism.

In addition to these developments, architectural discourse has become increasingly aware of the exponential growth of its possible tasks. This growing of tasks has obvious been a result of the industrial revolution and the emergence of capitalism, and as a result has meant that the original set of instructions defined in the history of architectural theory, which addressed a rather limited amount of possible architectural projects, no longer dealt with the entire range of (future) possible architectural action and, therefore, production. Theory had become rather ill-equipped to still provide for a systematic body of knowledge in a period during which a substantial 'division of labor' occurred. Furthermore, since the tasks of the architect were broadened, and even made explicitly open and flexible to allow for adjustments based on the logic of the market-economy, theory could no longer properly anticipate the architect's production a priori, but rather had to approximate these. As a result, and especially in recent decades, research has become an alternative to theory in providing another, distinct, rather specific and almost unrelated, set of knowledge and instruments resulting in architectural production. 
What is currently high on the agenda in this contemporary engagement with research is the elaboration of its role in relation to the architectural design project. A point of obvious critique when assessing these efforts is that the prescriptive role that was played out in architectural theory previously, is not very specifically elaborated upon in contemporary architectural research. This omission, or absence of clarifications, about the role research has in a design process is in need of being addressed. Nowadays, research is specifically used to describe the contextual preconditions of an architectural project. It sketches out the spatial, social, political and economical state of affairs related to a specific location; it addresses the specific types of knowledge coming out of these investigations; but it hardly ever addresses the way this knowledge is instrumentalized, conceptualized or made operational within an architectural design process. In other words, how forms of spatial analysis influence, in a direct or indirect way, the process of architectural design.

Architecture and the Problem of the Contemporary City The so-called "problem" of the contemporary city falls somewhat in line with the changed role of the architect in modernized times. Not only the activities of the architects have expanded and diversified, also their field of operation has diversified and multiplied. The modern metropolis had always evoked an impressive array of artistic and architectural responses, based mostly on the profound experiences of condensed space. In the last couple of decades, however, spatial experiences evoked by the contemporary city have been described using theories taken from the exact sciences (for instance chaos or catastrophe theory), and by implementing an equivalent terminology (using words such as complexity, network, multiplicity, topology and instability). This terminology marks the transition that has taken place in reflections on the urban condition, namely the shift from descriptions of the city as an undiversified space of densification, to descriptions that emphasize the city as a field of intensities and differentiation. As a result, the contemporary city has become viewed and thus theorized as a territorial entity of stratified ecologies, circumscribed by networks of relationships.

\section{Nowadays, research is specifically used to describe the contextual preconditions of an architectural project.}




\section{The contemporary city has become viewed and thus theorized as a territorial entity of stratified ecologies, circumscribed by networks of relationships.}

This revised interest in the city is precursed by the explorations of the American city initiated in the early Seventies. Boyarski, Banham as well as Venturi / Scott Brown / Izenour were the first to acknowledge and bring forward "the contemporary city" as a concrete and "real" subject of architectural investigation. Chicago, Los Angeles and Las Vegas are the subsequent first three examples where the characteristics and specificities of $a$ particular city were considered indicative towards a larger discursive understanding in architecture. The city as factual and real entity could potentially have certain properties that one could distill and project forward as basic principles of a contemporary architectural focus. Koolhaas had understood this probably the clearest, not only because of the retro-active manifesto of Manhattan he compiled within years after the three "city” manifesto's, but especially considering that his investigations of New York have remained the blue-print for constructing similar theoretical manifestoes with the fascinations for Atlanta, Lagos, and the Chinese/Asian generic city, which have turned this journalistic act into a specific methodology (Koolhaas, 1994).

Surely, one of the contradictions that came out of this period is the fact that the city as a whole is 'processed' towards a thematic proclamation, ignoring any kind of differentiation embedded within those cities themselves. The contradiction, here, is located in the fact that the end of the meta-narrations of postmodernity should have resulted in the clear conclusion of the sheer impossibility of such an endeavor. On the contrary though, Koolhaas's emblematic role in sublimating the general tendencies of New York in the $20^{\text {th }}$ century or Atlanta in the $21^{\text {st }}$, meant a simplification beyond reason when describing the city as a real model (though one must confess that these simplifications have had their importance when specifying and determining certain developments that were indicative and thus relevant for architectural discourse as a whole). On the other end of the spectrum, however, one can position for instance the work of the Situationists and be perplexed by their fragmentary understanding of the city and the simple fact that they did not even attempt to consider the city as a consistent whole. Rather, the fragmentary nature is not only being made explicit but is forced upon the 
city. The Guide psychogéographique de Paris and The Naked City maps ${ }^{2}$ are such powerful attempts that not only dissect the city in smaller bits and pieces, but transfigure it by detaching the parts that are spatially connected, thus arriving at an understanding of the city that offers a set of instructions of how to operate, maneuver and/or live in it.

\section{Research versus Design}

The need to address the expanding range of architectural production as well as the inherent complexities of the urban fields in which architecture operates, focuses the attention of contemporary research in architecture on the changing ways architectural production is conceived and perceived. The consequences of this changed perspective are rather extreme, as a radical reconsideration is required with respect to the employed techniques of design and spatial analysis, to the additional and related ways of understanding, interpreting, conceiving and representing architectural construct as well as to the theories with which the architectural object is understood. In this discursive constellation, the sets of relationships that can be constructed between these three modalities constitute the primary points of attention. Here, the diversity in modes of expression, which Tafuri considered problematic, turns into an appreciation of diversity. The heterogeneity that fundamentally lies at the basis of this intent includes the multiplicity of ideas that are not limited to the architectural discipline only, but might, or even should, be related to other discursive debates. This would imply the need for a clarification of the very limits of the discipline itself, making this kind of contemporary research in architecture speculative and ambiguous. Within this "border condition" of the discipline, a particular kind of decentering or disorientation is inevitable, if one were intending to change the orientation of the architectural discipline at least.

The general tendencies sketched thus far, namely the discursive developments towards increasingly multidisciplinary perspectives on architectural issues and activities; the need for overcoming the differences between spatial analysis (i.e. research) and architectural design; and the inexhaustible and in fact ever-expanding relationship of architecture with the city, converge
2 - Published in 1956 and 1957, respectively. The Naked City was first published in Asger Jorn's Pour la forme; ébouche d'une méthodologie des arts (Paris, Internationale situationniste, 1957). 
in the Border Conditions \& Territories (BC\&T) architectural research program, currently operating at the Faculty of Architecture in Delft (Netherlands) ${ }^{3}$. The program finds a common ground in the understanding that (1) the territorial and urban contexts are the primary forces that both influence and determine to a large extent the contemporary production of architectural construct and that (2) the underlying philosophical, cultural, political and aesthetic value systems both influence and determine to a large extent the meaning/significance of architectural production. The BC\&T research aims to both chart and relate these fields in order to establish the rules for and the reasons behind the complex spatial conditions, mechanisms and systems within contemporary cities and territories. Especially the specific, at times emergent, spatial conditions found in contemporary cities and territories are considered to be a rich field in need of exploration and ultimately comprehension. Within this programmatic set-up, a certain relationship is presupposed between architectural construct and the "grounding" of these constructs, both in terms of situational context and theoretical framework(s. The attempt to clarify and relate the act of architectural design to the contextual influences on that act originates from this presupposition.

The investigative structure explained above opens an intriguing perspective on the relationship between

When considering the contemporary attempts to relate design to research, different categories can be distinguished. research and design in architecture. When considering the contemporary attempts to relate design to research, as the fashionable term "research by design" would indicate, three different categories can be distinguished that describe the relationship between architectural research and architectural design: (1) to consider design as a specific form of research, thus considering the act of design itself as an investigative act; (2) to consider design as object of research, by concentrating on design as methodological process, thus describing design as a reasonably controlled procedural act; or (3) to clarify how research might potentially inform design, thus directly relating spatial investigation to the projective act of design. Following the arguments formulated thus far, it should be clear that the BC\&T research program is focusing primarily on this third category (without simultaneously dismissing the necessity to critically assess the overall 
relationship between research and design in architecture). In this research framework, tools of spatial analysis, whether operative or reflexive, are intrinsically related to architectural design acts. The methods used to analyze a context through spatial categories (be it cartographic, drawn, textual, digital, or otherwise) are related to the forms the architectural design act produces. In each of these cases, the undeniable relevance of a plurality of investigative and design approaches, mentioned before, is thus incorporated into a research framework that focuses on the relationship between the acts of research and design (hence the term "design by research" that opened this argument).

\section{Mapping (as an Index of Past and Future Possibilities)}

In this attempt to link spatial analysis to architectural design, mapping is considered to be one of the more, if not most, promising tools. When one glances through the historical and theoretical material focusing on maps and mapping in architectural discourse, one can discern a quite clear conclusive summary of the aspects relevant for the practices of map production in architecture: issues of scale, frame, selection (observation) and coding (notation) are geared towards the projection of three-dimensional space onto a two-dimensional surface or three-dimensional object, while relevant references to geometry, geography, topography, topology, and chorography ("place""writing") also play a role in this act. The potential of mapping as a tool to link spatial analysis to architectural design, however, has hardly been acknowledged by mapping scholars. Cosgrove, for instance, a scholar who has inexhaustibly dwelled on the importance of mapping in a wide variety of discourses, considered acts of mapping merely as «acts of visualizing, conceptualizing, recording, representing and creating spaces graphically» (Cosgrove, 1999: 1), while James Corner understood mapping as something that precedes the map, just as «order is the outcome of the act of ordering” (Corner, 1999: 229).

The profound and rich history of the discipline of cartography offers numerous examples of the art and science of map-making, as well as of the cultural and political ideologies that constitute their hidden agendas. Within this tradition, however, the difference between a 'map' and a 'mapping' has not often

\section{The potential of mapping as a tool to link spatial analysis to architectural design, has hardly been acknowledged by mapping scholars.}




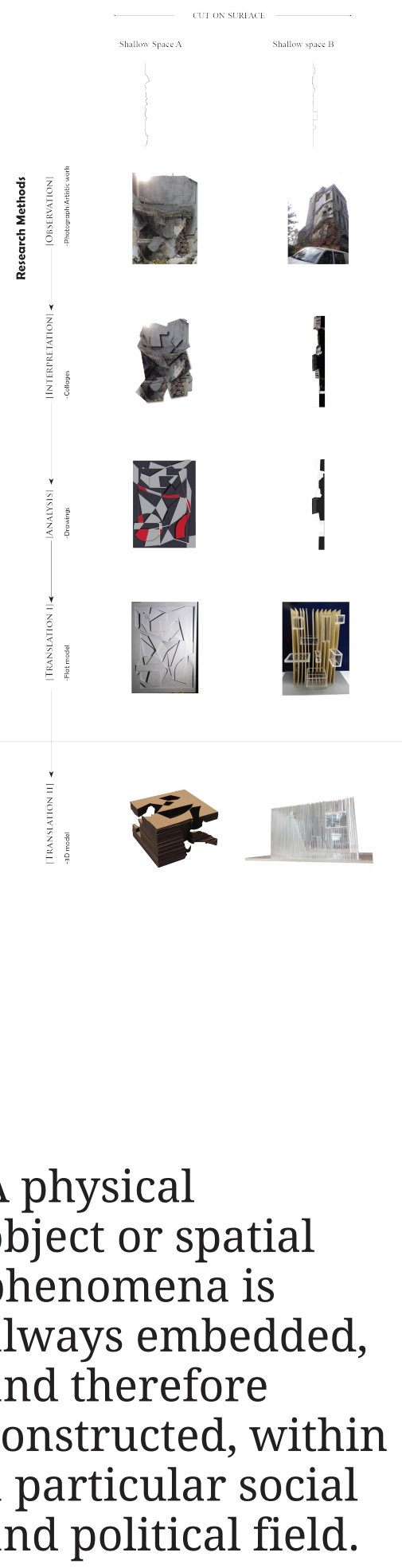

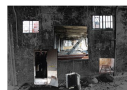
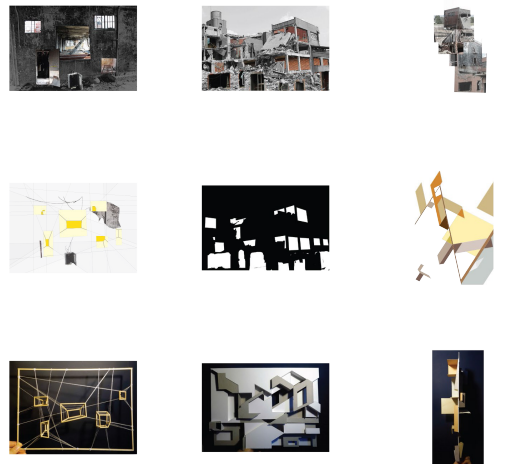
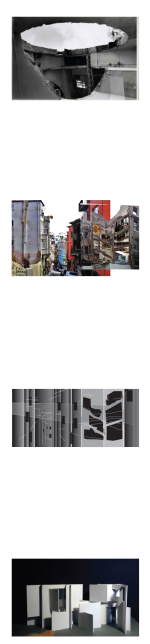

been made explicitly clear. Mapping can be seen as the act of making or producing a map, i.e. part of the active tense of a verb. But a mapping is also possible as noun, namely the result of the making of a map. "Mapping" can refer to the activated result of the making of a map, yet the Oxford dictionary (OED) also states that mapping, as noun, is used in mathematics and linguistics, and means «an operation that associates each element of a given set (the domain) with one or more elements of a second set (the range)». The relevance of mapping for architecture is in first instance located in the fact that mapping is a highly significant technique to explore and investigate the multiplicity of contemporary spatial conditions as a mapping is a representation of a social construct within a spatial frame(-work) while offering a means to navigate the space it represents.

A physical object or spatial phenomena is always embedded, and therefore constructed, within a particu- 


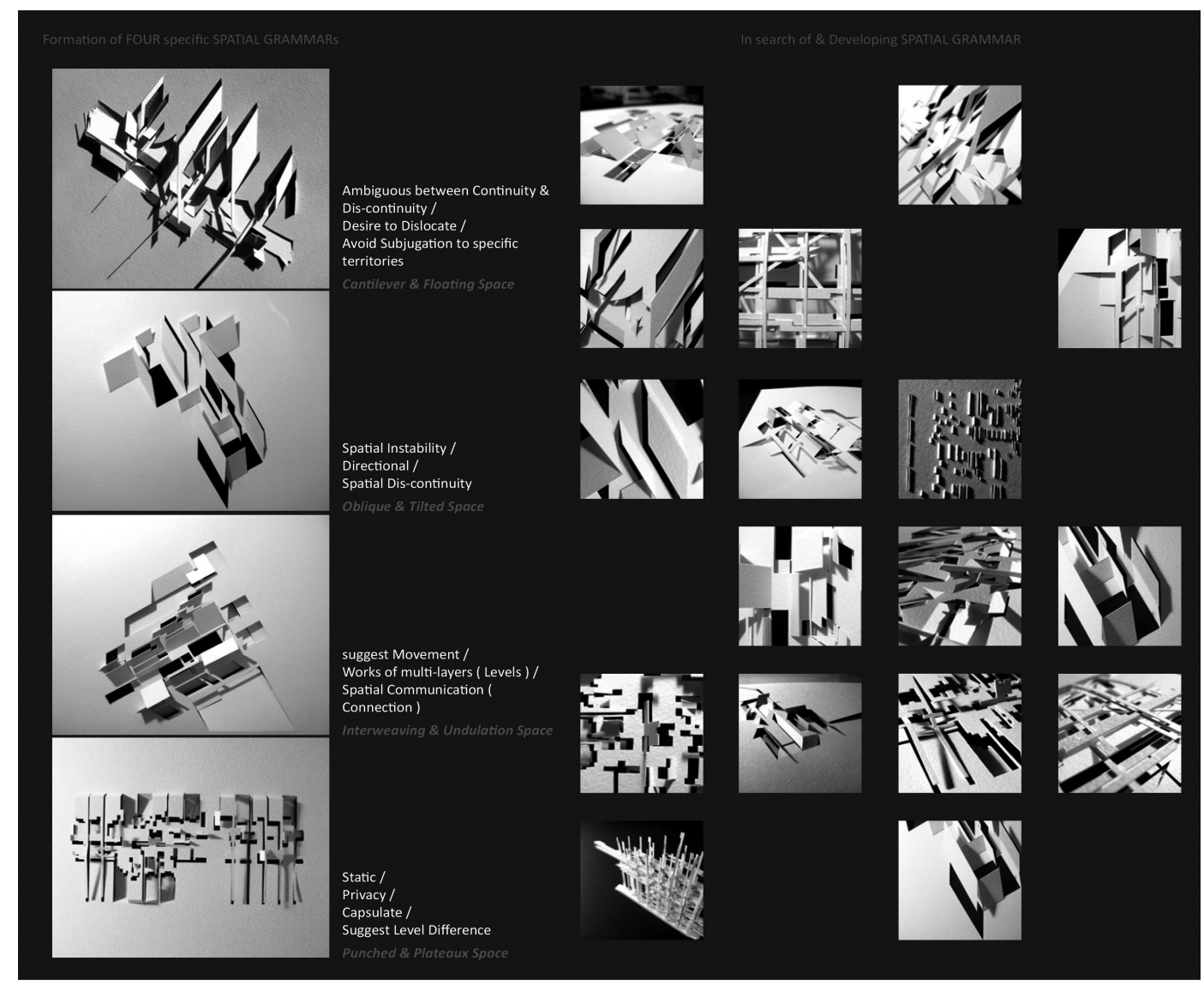

lar social and political field. Meanings emerge from mappings via engaged acts of reading, mining possible multiplicities and vitalities out of the field of represented relations. What precedes the map, to be precise, is a selection process vis-à-vis the complexity of the world in which a decision is made as to what will be represented (and what not) (Harley, 2001: 51-81). The fundamental difference between a map and a mapping is that the map offers a continuous surface or field description, while a mapping constructs a place-time discontinuity in the description and understanding of a spatial condition. This place-timediscontinuity of a mapping constitutes a distortion that obscures the regularities of Cartesian space and disrupts the chronological sequences of time, making mapping the discontinuous unfolding of "a place" and "a duration". Furthermore, since discontinuity introduces a disfiguring of a place-order and a timesequence and since a map implies a systematic way of 


\section{There are}

\section{numerous}

examples of urban analyses that have

been part of, the design process, but the findings of these urban investigations hardly constitute guiding design principles for an architectural intervention. measuring space, discontinuity means an adjustment in the way measurement is employed in map coding. As every mapping simultaneously offers registrations of reality-as-found and indications of possible future interventions, the potential of mapping as a 'design by research’ strategy needs to be acknowledged but also specified.

Methods of mapping have been employed to make immanent spatial conditions 'accessible' for architectural construct on a few of occasions in architectural history. In these instances, special attention is given to the development of specific cartographic techniques enabling the registration of architectural form and/or the interpretation of urban spatial processes. In these cases, mapping is considered exceptionally relevant to this end, for the map becomes in many ways a nearly tangible place: a territory that is measured, circumscribed and demarcated. Nevertheless, even though mapping has been discussed at length in the past two decades, conspicuously absent in these discussions is the potential relationship that mapping actually might have with architectural design, not as a supporting tool, but rather as an integral part of the design process. There are numerous examples of urban analyses that have been part of, or incorporated in, the design process, but the findings of these urban investigations hardly constitute guiding design principles for an architectural intervention. Almost all examples in architectural discourse emphasize the urban context of architecture either via the collection of information (mapping as data visualization) or through an analysis of its formal principles (figure-ground maps or urban plan maps), but what remains absent is both a design theory that outlines how these research and design might be related.

\section{A "Design by Research" Theory}

How, then, to develop the foundations for such a theory that relates architectural research to design, and out of which principles or guidelines for architectural design can be developed? How, more specifically, can cartographic means enable architects to chart characteristics of space and, as a consequence, "enable" mapping to potentially inform architectural construct? The starting point of this line of reasoning would have to be that the employment of mapping in 
architectural design is in essence an activation of the map towards architectural construct. And, in addition, that this activation of spatial analysis is both projective and performative. Moreover, as a third step, this activation that is being set in motion through mapping can be distinguished as basically being an instrumentalization, an operationalization or a conceptualization of the map. As is thus proposed here, these three basic principles of activation are to be specified when theorizing the way spatial analysis through mapping informs architectural construct.

With respect to the first form of map activation mentioned, instrumentalization means "being rendered instrumental (to direct, organize, adapt)" or "being transcribed for instrumental execution". To use mapping for "instrumental execution" is, in other words, a form of activation whereby "transcription" is the means with which the map is put to use. The architectural instrumentalization of the map works via transcription, which is in first instance the specific notation or coding system within the mapping, intended to depict a specific understanding of a specific part of "the human world". Apart from this transcriptive act in mapping (namely from observation via interpretation to notation), an additional transcription takes place when the notation system developed in and for the mapping is subsequently "transcribed" into a formal language (or simply "form"). Bernard Tschumi's Manhattan Transcripts presents one of the more important attempts at developing this kind of mapping technique in relation to an architectural language (Tschumi, 1994). The Transcripts intended to address a radical shift in the architectural understanding of the nature of the city: no longer interested in unity, they accepted a certain fragmentation and incompleteness in the contemplation of the city and introduced the moment of time in the reading (and understanding) of the city. Instead of referring to the past material and materiality of architecture, namely as neutral, objective, indifferent objects, the Transcripts deliberately aim at architectural form being biased, subjective and inviting for a participatory engagement with that material («[...] you may even need to commit a murder»). What is produced in a mapping is a representation that introduces an indirect relationship, and no longer constitutes a one-to-one rela-

\section{To use mapping for "instrumental execution” is, in other words, a form of activation whereby "transcription" is the means with which the map is put to use.}


To initiate an exploratory search for a "point of entry" or a "moment of emergence" for an architectural project. tionship, between "thing" and "line". Therefore, the instrumentalization of the map works towards the distinctive architectural disciplinary act of production, namely towards architectural form emerging from the development of a specific system of notations.

Through operationalization, which is the second form of map activation theorized here, the activation of the map is employed to no longer construct the disciplinary autonomy of 'original meanings and significations' of an architectural project (which is traditionally the informative, supportive, yet distanced and less critical role of research in architectural design processes), but to initiate an exploratory search for a "point of entry" or a "moment of emergence" for an architectural project. This exploratory search enables the more experimental role that research can play in an architectural design process, by allowing for a design strategy that is rigorously open to the possibilities of becoming, of imagination, and of experience. Such an open-ended design strategy constructs knowledge through a bottom-up process, rather than implementing knowledge in a top-down manner. Moreover, through the notions of 'entry point' and 'emergence moment' of the exploratory search embedded in mapping, the characteristics of 'place' and 'time' will almost inevitably be incorporated in a design process. As a result, the architectural design process that is instigated through a research by mapping extends the initial open-ended question of the architectural project by incorporating the state of uncertainty regarding the object under study and the process of design itself. An exemplary mapping in this context is Daniel Libeskind's Star of David Matrix, which was part of his original Between the Lines competition entry (that later became the Jewish Museum) ${ }^{4}$. In this particular mapping of Berlin, the map activation introduces several forms of differentiation through the implementation of measurement and this particular measured differentiation initiated an operationalization of the map's content towards a conceptual idea, which is substantiated by both the lines of the matrix and the line of the Berlin Wall. The result is an elaboration of the discontinuity within the mapping, which is consequently addressed by absence, void and silence in more than the one straight line that literally voided the Museum's structure in its built form (see, for in- 
stance: Libeskind, 1991). More precisely, the bringing together of substance in this mapping has preceded and guided the design process, precisely because the absent is present as a potentiality and/or a possibility, not as a literal absence, allowing for the very 'idea' of the architectural project to emerge. In other words, this particular form of map activation introduces an 'operation' that works towards the distinctive architectural disciplinary act of producing a projective idea via the development of a specific measuring of differences.

The conceptualization of the map, the third form of map activation to be discussed in this context, enables the production of architectural theory, which is achieved through the development of a specific system of ordering implemented in the mapping. This system of ordering has similarities with the architectural tradition of constructing urban maps that depict the urban condition in its totality, but in contrast to mapping, these urban maps not only frame and order the city, but also fix the architectural objects as distinct singularities within a static field of differences. One of the intrinsic characteristics of mappings is that they create a reality that may lie beyond the realm of physical and material facts. The recent developments in contemporary mapping underlines the tendency to integrate ephemeral characteristic of space with more tangible (or physical) aspects incorporated in the depiction of urban conditions. Within such a mapping set-up, the measurement of spatial objects, forces and fields occurs via a means of representation that traces, maps and positions these spatial phenomena and constitutes the very basis of forming, gathering and constructing knowledge. Architecture is gathering, the bringing together of differences within one framework. As stated previously, the contextual aspect of architectural production addresses the circumstances of architectural construct and should be understood in different, equally important ways, namely as the origin of architectural production; as the historical framework, explicating the political, social, physical, architectural conditions surrounding its emergence; but also as theoretical framework, incorporating the historical developments of thought within the constellation the work produces. In addition, then, the concept of "order" should be understood, in first instance,
Submitted under code: 6000000 . Information from the Daniel Libeskind papers, 1968-1992, located at the Special Collections department of the Getty Research Institute in Los Angeles. Inquiring the reasoning behind the ETA Hoffmann reference for the Exile Garden, Vera Bendt concluded: «Mit Hilfe astrophysischer Terminologie und mathematisch anmutenden Koordinatensystemen stellte der Architekt nach seinem Belieben aus der Vielzahl von Namen, historischen Orten und Ereignissen in der Geschichte Berlins ein architektonisches Bezugsfeld auf, um seine frühen dekonstruktivistischen Arbeiten an das Museumsprojekt zu adaptieren". See: Vera Bendt, Wahnsinnige Wissenschaft, E.T.A. Hoffmann, Exil und das Jüdische Museum Berlin, in: E.T.A. Hoffmann Jahrbuch, band 8, 2000: 135. Vera Bendt is the former director of the Jewish Museum Department of the Berlin Museum and co-author of the competition brief for the Extension of the Berlin Museum with the Jewish Museum Department. 


\section{The}

conceptualization of the map, enables

the production of architectural theory, which is achieved through the development of a specific system of ordering implemented in the mapping.

\section{Mappings are artistic fabrications that can potentially become performative tools for architectural production since they activate the projected complexities.}

as the architectural notion of composition, which has historically been quite frequently object of formal analysis. However, order is also spatial disposition, taxonomy, catalogue, organization, and program. Through their gathered heterogeneity of juxtapositions and superimpositions, mappings are artistic fabrications that can potentially become performative tools for architectural production since they activate the projected complexities of the spatial features of an urban or territorial condition. By offering an implemented ordering that is projected into the mapping, in other words, architecture becomes performative since it (spatially) orders plurality.

\section{References}

Boyarsky, A. (1970), Chicago à la carte: The City as Energy System, "Architectural Design", December.

Banham, R. (2001), Los Angeles. The Architecture of Four Ecologies, Berkeley - London, University of California Press (original: 1971).

Corner, J. (1999), The Agency of Mapping: Speculation, Critique and Invention, in D. Cosgrove (ed.), Mappings, London, Reaktion Books.

Cosgrove, D. (1999), Introduction: Mapping Meaning, in D. Cosgrove (ed.), Mappings, London, Reaktion Books.

Durand, J.N.L. (2005), Précis de leçons d'architecture données à l'École Royale Polytechnique (1802), in H.F. Mallgrave (ed.), Architectural Theory, Volume I - An Anthology from Vitruvius to 1870, New Jersey, Wiley-Blackwell.

Harley, J.B. (2001), The New Nature of Maps; Essays in the History of Cartography, Baltimore-London, The John Hopkins University Press.

Jorn, A. (1957), Pour la forme; ébouche d'une méthodologie des arts, Paris, Internationale situationniste.

Koolhaas, R. (1994), Delirious New York; A Retroactive Manifesto for Manhattan, Rotterdam, 010 Publishers (original: 1978).

Libeskind, D. (1991), Countersign, London, Academy Editions (“Architectural Monographs", n. 16).

Lyotard, J.-F. (1984), The Postmodern Condition: A Report on Knowledge, Minneapolis, University of Minneapolis Press (original: La Condition postmoderne: rapport sur le savoir, Paris, Les Editions de Minuit, 1979).

Papadakis, A., Cooke C, Benjamin, A. (eds.) (1989), Deconstruction, Omnibus Volume, London, Academy Editions. Tafuri, M. (1976), Architecture and Utopia; Design and Capitalist Development, Cambridge-London, The MIT Press (original: Progetto e Utopia, Bari, Laterza, 1973; translated by B.L. La Penta). 
Tafuri, M. (1979), Main Lines of the Great Theoretical Debate over Architecture and Urban Planning, 1960-1977, “A+U”, n. 1, pp. 142-161.

Tschumi, B. (1994), The Manhattan Transcripts, London, Academy Editions.

Venturi, R., Scott Brown, D., Izenour, S. (1996), Learning from Las Vegas: The forgotten Symbolism of Architectural Form, Cambridge (MA) - London, The MIT Press (original: 1972).

Vitruvius, Marcus (1960), The Ten Books of Architecture, New York, Dover Publications.

Wigley, M. (1993), The Architecture of Deconstruction; Derrida's Haunt, Cambridge (MA) - London, The MIT Press. 